\title{
Palatal and pharyngeal reflexes in health and in motor neuron disease
}

\author{
T A T Hughes, C M Wiles
}

\begin{abstract}
Palatal and pharyngeal sensation and motor responses, and volitional palatal movement, were tested in 171 healthy adults and 43 patients with motor neuron disease. In healthy adults palatal and pharyngeal sensation and volitional palatal elevation were present in all; the palatal and pharyngeal motor responses could not be elicited on first testing in two $(1 \cdot 1 \%)$ and seven $(4 \cdot 1 \%)$ subjects respectively. Pharyngeal motor responses were more easily elicited in older subjects and palatal responses were more easily elicited in women. Eye watering and retching were the most common accompanying features. In 57 normal subjects tested on five occasions there was considerable variation in the stimulus required to elicit the motor responses within subjects: in none of four subjects $(7 \%)$ who initially had absent responses were they always absent. Pharyngeal motor responses were more easily elicited in patients with motor neuron disease than in matched normal subjects; within the motor neuron disease group pharyngeal motor responses elicited by tongue depression were associated with the symptom of food or drink "going down the wrong way" $>1 /$ month and a reduction in average volume per swallow $(\mathrm{ml})$ and swallowing capacity $(\mathrm{ml} / \mathrm{s})$. Volitional palatal elevation was absent in five patients $(11.6 \%)$. In six of eight patients with motor neuron disease studied repeatedly (on between two and seven occasions) the palatal and pharyngeal responses were elicited with the same stimulus on each occasion. In healthy adults palatal and pharyngeal sensation and motor responses should be present although considerable variation occurs in the stimulus required. In patients with motor neuron disease features of impaired swallowing are associated with a brisk rather than a depressed pharyngeal response.
\end{abstract}

\section{(F Neurol Neurosurg Psychiatry 1996;61:96-98)}

Keywords: gag reflex; motor neuron disease; dysphagia $\mathrm{T}$ A $\mathrm{T}$ Hughes $\mathrm{C} M$ Wiles

Correspondence to: Professor Wiles.

Received 11 August 1995 and in final revised form 11 March 1996 Accepted 20 March 1996 Definitions of the motor component of the gag reflex vary but may include palatal elevation, pharyngeal wall contraction, withdrawal of the head, coughing, retching, and eye watering. Stimuli used to elicit these responses also vary and the lack of a standardised method for testing the sensory and motor components of the gag reflex and of a detailed description of the responses seen in healthy men and women of different ages creates difficulty in interpretation of results in patients.

We have studied the palatal and pharyngeal responses, their repeatability, and the accompanying features, in a group of normal adults and in a group of patients with motor neuron disease.

\section{Methods}

\section{SUBJECTS}

One hundred and seventy one healthy adult volunteers (87 men, median age $47 \cdot 3$ (range 18.9-87.6) years and 84 women, median age 58.0 (range $18.9-91 \cdot 3$ ) years), including a minimum of nine men and nine women in each 10 year band between 15 and 75 years, and aged $\geqslant 75$ years), were recruited from hospital staff and the general public. All had answered "no" to the question "Do you have a problem with your swallowing?" and were screened for medical, surgical, and neurological problems known to affect swallowing; they formed the normal group in this study. Forty three patients (23 men, median age 64.9 (range $49 \cdot 7-83.4$ ) years, 20 women, median age $69 \cdot 1$ (range $50 \cdot 8-85 \cdot 3$ ) years) with motor neuron disease formed the motor neuron disease group. Patients were seen a median (range) of $0 \cdot 16(0-9 \cdot 14)$ years after first presentation to a neurologist. The study was approved by the ethics committee of the South Glamorgan Health Authority and all subjects gave written consent.

\section{TECHNIQUES}

All subjects completed a questionnaire about swallowing and underwent a neurological examination.

To test sensation subjects, seated upright, were asked to close their eyes, open their mouths, and lift the ipsilateral hand when they first felt the touch of the tip of an orange stick applied consecutively to the right and left side of the soft palate and to the right and left side of the posterior pharyngeal wall.

Subjects rested for $10-15$ seconds before we 
responses. The palatal response was defined as an upwards movement of the soft palate; the amplitude of the movement was not considered. The pharyngeal response was defined as a visible contraction of the pharyngeal wall; in some subjects a definite movement towards the midline occurred whereas in others the pharyngeal wall seemed to become tense and corrugated but medialisation was less obvious. The responses were graded by the adequate stimulus. The least stimulus was depression of the tongue with a tongue depressor (grade 1); responses seen before any tongue contact were also described as grade 1 . To increase the stimulus tongue depression was combined with touching or stroking of the soft palate (grade 2) or posterior pharyngeal wall (grade 3 ) with an orange stick. If palatal or pharyngeal responses could not be elicited by firm depression of the tongue and repeated vigorous stroking of the posterior pharyngeal wall with the tip of an orange stick they were described as absent (grade 4). The least stimulus seen to elicit the responses during the examination was recorded.

When it was not possible to establish whether certain features were present or not the responses were recorded as "unable to see" or "unable to test". In subjects with initially absent responses up to four or five attempts were made to elicit them before declaring them absent.

Head withdrawal, eye watering, coughing, and retching were each documented as present or absent during and immediately after (within 1-3 seconds) attempts to elicit the motor responses.

Voluntary palatal movement was tested by observing the soft palate as the patient phonated; any upward movement of the soft palate was accepted as positive.

All healthy subjects completed a timed test of swallowing ${ }^{12}$ using non-carbonated bottled

Frequency of the different components of the gag reflex in three groups

\begin{tabular}{|c|c|c|c|c|c|}
\hline Component & & $\%$ Normal & $\begin{array}{l}\text { \% Normal } \\
>55 y\end{array}$ & $\% M N D$ & Pvalue \\
\hline \multirow{2}{*}{ Palatal sensation } & Present & $100 \cdot 0$ & $100 \cdot 0$ & $97 \cdot 7$ & \\
\hline & Absent & 0.0 & 0.0 & 0.0 & \\
\hline \multirow[t]{2}{*}{ Pharyngeal sensation } & Present & $94 \cdot 2$ & $90 \cdot 4$ & 86.0 & \\
\hline & Absent & 0.0 & 0.0 & 0.0 & \\
\hline \multirow[t]{3}{*}{ Palatal elevation } & 1 & $26 \cdot 3$ & $33 \cdot 7$ & $58 \cdot 1$ & $<0.05^{\star}$ \\
\hline & 2 & $45 \cdot 0$ & $43 \cdot 3$ & $32 \cdot 6$ & \\
\hline & 3 & $24 \cdot 0$ & $19 \cdot 3$ & $\begin{array}{l}7 \cdot 0 \\
0 \cdot 0\end{array}$ & \\
\hline \multirow[t]{4}{*}{ Pharyngeal contraction } & $\begin{array}{l}4 \\
1\end{array}$ & $\begin{array}{l}1 \cdot 2 \\
6 \cdot 4\end{array}$ & $\begin{array}{r}0.0 \\
12 \cdot 0\end{array}$ & $\begin{array}{r}0.0 \\
53.5\end{array}$ & $<0.001^{\star}$ \\
\hline & 2 & 40.9 & $38 \cdot 6$ & $34 \cdot 9$ & \\
\hline & 3 & $36 \cdot 3$ & $30 \cdot 1$ & 7.0 & \\
\hline & 4 & $4 \cdot 1$ & $3 \cdot 6$ & 0.0 & \\
\hline \multirow{2}{*}{ Palate on vocalisation } & Present & $99 \cdot 4$ & $100 \cdot 0$ & $86 \cdot 0$ & $<0.01 \dagger$ \\
\hline & Absent & 0.6 & 0.0 & $11 \cdot 6$ & \\
\hline Head withdrawal & Present & $22 \cdot 8$ & $10 \cdot 8$ & $30 \cdot 2$ & $<0.01 \dagger$ \\
\hline \multirow{2}{*}{ Eye watering } & $\begin{array}{l}\text { Absent } \\
\text { Present }\end{array}$ & $\begin{array}{l}74 \cdot 3 \\
64 \cdot 9\end{array}$ & $\begin{array}{l}85 \cdot 5 \\
54 \cdot 2\end{array}$ & $\begin{array}{l}67 \cdot 4 \\
44 \cdot 2\end{array}$ & $>0.2 t$ \\
\hline & Absent & $32 \cdot 2$ & $42 \cdot 2$ & $51 \cdot 2$ & \\
\hline Coughing & Present & $10 \cdot 5$ & $18 \cdot 1$ & $\begin{array}{r}9 \cdot 3 \\
88 \cdot 4\end{array}$ & $>0 \cdot 2 \dagger$ \\
\hline \multirow[t]{2}{*}{ Retching } & $\begin{array}{l}\text { Absent } \\
\text { Present }\end{array}$ & $\begin{array}{l}80 \cdot 7 \\
25 \cdot 1\end{array}$ & $\begin{array}{l}78 \cdot 3 \\
37 \cdot 3\end{array}$ & $\begin{array}{l}88 \cdot 4 \\
51 \cdot 2\end{array}$ & $>0.1 t$ \\
\hline & Absent & 71.9 & $59 \cdot 0$ & $46 \cdot 5$ & \\
\hline
\end{tabular}

$\mathrm{n}=171$ for normal subjects; $\mathrm{n}=83$ (38 men, median age (range) $68.8(56 \cdot 5-87 \cdot 6)$ years), 45 women 67.2 years $(55.4-91 \cdot 3)$ years for normal subjects aged $\geqslant 55$; and $n=43$ for the motor neuron disease group. The few subjects in whom the reflexes or accompanying features could not be tested account for the shortfall in \% for each feature.

${ }^{\star} \chi^{2}, 3 \times 2$ contingency tables for grades 1,2 , and $3 v$ normal subjects aged $\geqslant 55 \mathrm{y} /$ patients with motor neuron disease.

†Fisher's exact test or $\chi^{2}$ with Yates' correction, $2 \times 2$ contingency tables for component present or absent $v$ normal subjects aged $\geqslant 55 \mathrm{y} /$ patients with motor neuron disease. water at room temperature; those aged $<75$ years were given $150 \mathrm{ml}$, those aged $\geqslant 75$ years $100 \mathrm{ml}$. Forty one patients with motor neuron disease completed a timed test of swallowing using tap water at room temperature: the volume given ranged from $10-150 \mathrm{ml}$ depending on the clinical state of the patient.

\section{REPEATABILITY OF THE RESPONSES}

Healthy subjects willing to undergo a series of studies were invited to do so; 57 ( 33 men, median age (range) 49.6 (20.0-79.0) years and, 24 women, median age (range) $56.8(21.2$ 83.9) years) completed three examinations on the first day at two hourly intervals, one a week later, and a final examination after a further week.

Eight subjects with motor neuron disease (three women aged 52 (two) and 55 years, five men aged 54, 62 (two), 68, and 77 years) completed more than one examination. The number of examinations performed, with the number of subjects in parentheses, was as follows; two (one patient), three (one), 4 (two), five (three), and seven (one). The maximum number of separate examinations performed on one day was three.

\section{STATISTICAL ANALYSIS}

Fisher's exact test or $\chi^{2}$ analysis with Yates' correction were used to analyse contingency tables.

\section{Results}

\section{NORMAL SUBJECTS}

Pharyngeal and palatal sensation were present in all those who could be tested (table).

On first testing, a palatal motor response could not be elicited in two $(1 \cdot 2 \%)$ or a pharyngeal motor response in seven (4.1\%, table). The pharyngeal response required the pharyngeal wall to be touched more often, and was elicited by tongue depression alone less often, than the palatal response (table). Proportionately more older ( $\geqslant 55$ years) than younger $(\leqslant 55$ years) subjects had a pharyngeal response after depression of the tongue alone $(P<0.01)$; the same was true of the palatal response in women compared with men $(\mathrm{P}<$ $0 \cdot 05)$. Eye watering was the most common accompanying feature, followed by retching; eye watering and coughing became more common as the stimulus applied increased. Voluntary palatal elevation was present in all.

\section{MOTOR NEURON DISEASE GROUP}

The palatal and pharyngeal responses were brisker than in normal subjects aged $\geqslant 55$ years-that is, elicited more often with tongue depression alone $(P<0.05$ and $P<0.001$ respectively). In five $(11.6 \%)$ patients with motor neuron disease voluntary palatal elevation was absent. There was no difference in accompanying features related to the grading of the responses. Head withdrawal was less common in the normal group than in the motor neuron disease group $(P<0.01)$. The symptom of food or drink going down the wrong way 
more than once a month was associated with a brisker pharyngeal response $(P<0.05)$.

Swallowing capacity and average volume per swallow of each subject in the normal and motor neuron disease groups were expressed as $\%$ predicted according to age and sex. ${ }^{1}$ The results in those with grade 1 palatal and pharyngeal responses were compared with those with grade 2 and 3 responses combined. In normal subjects there was no difference in the \% predicted average volume per swallow or the \% predicted swallowing capacity (Kruskal-Wallis test; $P>0 \cdot 1$ for all). In motor neuron disease a grade 1 pharyngeal response was associated with a reduction in \% predicted average volume per swallow and swallowing capacity (Kruskal Wallis test; $\mathrm{P}=0.017$ and $\mathrm{P}=0.026$ respectively).

\section{REPEATABILITY}

None of the $\mathbf{5 7}$ healthy subjects had an absent palatal or pharyngeal response on all five occasions. Thirty subjects had a grade 1 palatal response and 32 a grade 3 response among their five responses; 11 subjects had both. For the pharyngeal response 13 subjects had a grade 1 and 38 a grade 3 among their five responses but only five subjects had both. The stimulus to elicit a palatal response was the same over five examinations in 13 subjects; in 32 it varied by one grade and in 12 by up to two grades. The stimulus to elicit the pharyngeal response did not vary in 19 subjects; in 31 it varied by one grade, in five by up to two grades, and in one by up to three grades.

In eight patients with motor neuron disease who underwent repeat examinations the palatal response was elicited with the same stimulus on each occasion tested in six patients (grade 1 in five) and varied by up to one grade in one patient and by two grades in another; exactly the same applied for the pharyngeal response which in each patient was always elicited with the same stimulus as the palatal response.

\section{Discussion}

Much published work concerning the gag reflex lacks a clear description of the exact method for examining the responses and for defining normal and abnormal; ${ }^{34}$ two standard textbooks of neurology contain contradictory descriptions of the pharyngeal response. ${ }^{56}$

This study recorded the responses seen in alert healthy adults and in patients with motor neuron disease; the discussion might not apply to patients with other neurological diseases or a depressed conscious level.

We did not find any normal subject with absent palatal or pharyngeal sensation; this finding is in agreement with others. ${ }^{7}$ However, we did not find any subject who had consistently absent palatal and pharyngeal motor responses; previous studies have suggested that many normal subjects have an absent gag reflex. ${ }^{89}$ The subjects in these two studies presumptively had normal swallowing and phonation, normal voluntary palatal elevation, and normal sensation and it is unlikely that the req- uisite lower motor neuron pathways for the palatal and pharyngeal responses were impaired. The likely explanation for finding absent responses in many normal conscious subjects would seem to be either an inadequate stimulus or the presence of situational factors which might cause increased descending (supranuclear) inhibition, as is known to occur in cough. ${ }^{10}$

The grading system disclosed some differences in the responses related to age and sex in healthy adults; a brisker palatal response in women has not been described before and unlike other investigators ${ }^{8}$ we found a brisker pharyngeal response in older rather than younger subjects.

Within the motor neuron disease group a brisk pharyngeal response was associated with a symptom suggestive of a swallowing problem and a significant reduction in two ratio measures of swallowing. There may be many reasons for this finding. Patients who are aware that their swallowing is abnormal may develop a heightened sensitivity to objects in the mouth and pharynx and their threshold for initiating protective responses may become lower. Alternatively loss of corticobulbar pyramidal fibres may lead to brisker palatal and pharyngeal responses due to a reduction in descending inhibition; if such loss also impairs behavioural modulation and control of swallowing it may explain the association found between a brisk pharyngeal response and indicators of more abnormal swallowing.

Repeat examinations in 57 subjects demonstrated for the first time how variable the responses could be within individual subjects even when examined by the same examiner.

In conclusion, absent palatal and pharyngeal sensation or persistently absent palatal and pharyngeal responses in a conscious subject are very unusual and may merit further investigation; the associated effect on bulbar function will depend on whether there is an underlying cause. In motor neuron disease a brisk rather than a depressed pharyngeal response is associated with more impaired swallowing.

TATH was sponsored by Procter and Gamble Health and Beauty Care Limited. We are grateful to Dr R Eccles, Director, Beauty Care Limited. We are grateful to Dr R Eccles, Director,
Common Cold Centre, Cathays Park, Cardiff and all the volunteers who took part in this study.
temon Cold Centre, Cathays

1 Hughes TAT, Wiles CM. Clinical measurement of swallowing in health and in neurogenic dysphagia. $Q \mathcal{F} \mathrm{Med}$ ing in health

2 Nathadwarawala KM, Nicklin J, Wiles CM. A timed test of swallowing capacity for neurological patients. $\mathcal{f}$ Neurol Neurosurg Psychiatry 1992;55:822-5.

3 Horner J, Massey EW, Brazer SR. Aspiration in bilateral stroke patients. Neurology 1990;40:1686-8.

4 Horner J, Massey EW. Silent aspiration following stroke. Neurology 1988;38:317-9.

5 Bickerstaff ER, Spillane JA. Neurological examination in clinical practice. 5th ed Oxford: Blackwell Scientific Publications, 1989:85-9.

6 Adams RD, Victor V. Principles of neurology. 5th ed. New York: McGraw-Hill, 1993:1177-80

7 Moulton C, Pennycook AG. Relation between Glasgow coma score and cough reflex. Lancet 1994;343:1261-2.

8 Davies AE, Kidd D, Stone SP, MacMahon J. Pharyngea sensation and gag reflex in healthy subjects. Lancet 1995 345:487-8.

Kulig K, Rumack BH, Rosen P. Gag reflex in assessing level of consciousness. Lancet 1982;i:565.

10 Hutchings HA, Morris S, Eccles R, Jawad MSM. Voluntary suppression of cough induced by inhalation of capsaicin in suppression of cough induced by inhalation of caps
healthy volunteers. Respir Med 1993;87:379-82. 